\title{
Las fronteras de los archivos. Lo exótico en Pasolini.
}


THE BORDERS OF THE ARCHIVES. THE EXOTIC IN PASOLINI.

\section{ABSTRACT}

Today Pier Paolo Pasolini is considerated as one of the most important Italian intellectuals from the 20th century. His life picks up the passage from the fascist regime to the neo-capitalism and from the colonialism to the post colonialism. Holding the actual Italian geopolitical context in mind in regard to the migration policies, the neoliberal and neocolonial development $¿$ what does analyse the pasolinianan reference mean now a day? And what happens in regard to the imaginary that was build around the poet as an icon of the fight against radical anti-capitalism if by analyzing his work and life we move our attention to an antiracist perspective? The objetive of this contribution is to situate the pasolinianan figure in the Italian historical context. Analysing his interest about archives and making the more orientalist aspect of his work.

\section{Keywords}

Pier Paolo Pasolini; visual anthropology; posexotic; geopolitics of memory; situated knowledge. 


\section{LAS FRONTERAS DE LOS ARCHIVOS. LO EXÓTICO EN}

PASOLINI.

\section{RESUMEN}

Hoy se considera a Pier Paolo Pasolini como uno de los intelectuales italianos más importantes del siglo XX. Su vida recoge el pasaje desde el régimen Fascista al neocapitalismo y del colonialismo al poscolonialismo.

Si tenemos en cuenta el contexto geopolítico italiano actual con respecto a las políticas migratorias y al desarrollo neoliberalista y neocolonial ¿qué significa analizar la referencia pasoliniana hoy? ¿y qué ocurre con el imaginario que se ha construido acerca del poeta como icono de la lucha anticapitalista radical si al analizar su obra y su vida desplazamos nuestra mirada hacia una perspectiva antirracista? El objetivo de esta contribución es situar la figura pasoliniana en el contexto histórico italiano, analizar su interés sobre los archivos y visibilizar el aspecto más orientalista de su obra.

\section{Palabras Clave}

Pier Paolo Pasolini; antropología visual; posexótico; geopolítica de la memoria; conocimientos situados. 


\section{INTRODUCCIÓN}

Esta contribución nace a raíz de la necesidad de releer, en clave feminista y anticolonial, a nuestros referentes culturales entendidos como elementos de construcción de la memoria colectiva italiana y occidental contemporánea. Nuestro interés se centra, especialmente, en la figura del intelectual italiano Pier Paolo Pasolini y en algunos aspectos de su obra literaria y cinematográfica, en concreto aquellos relacionados con el África nororiental.

Hoy, más de cuarenta años después de su muerte, Pier Paolo Pasolini es considerado como uno de los intelectuales italianos más importantes del siglo XX. Aclamado poeta, escritor y director de cine, también destacó como referente homosexual y antifascista. Pasolini fue alguien discordante en la cultura italiana de ese momento. Su vida recoge la etapa de tránsito entre el régimen fascista y el neocapitalismo; así como el paso del colonialismo al poscolonialismo. Para nosotras el trabajo de Pasolini podría considerarse un ejemplo de práctica auto-etnográfica que refleja los cambios culturales que se dieron en el contexto italiano desde los años cuarenta hasta los años setenta del siglo pasado. Pero, al mismo tiempo, su producción poético-cinematográfica relacionada con la otredad permite evidenciar una continuidad cultural vinculada a referencias latinas, griegas y a valores romanos y cristianos que han influido la construcción posterior de la italianidad contemporánea. Esta construcción identitaria se ha dado a través de algunos procesos culturales de naturaleza colonialista que empiezan con la unificación del país y que tocan la cuestión meridional interna a la península, sus proyecciones en el Cuerno de África y sus articulaciones con la modernidad.

Si tenemos en cuenta el contexto geopolítico italiano actual y su relación con las políticas migratorias, el desarrollo neoliberal y neocolonial, ¿qué significaría analizar la referencia pasoliniana hoy? Y ¿qué ocurre con el imaginario que se ha construido desde los movimientos de izquierda o de liberación sexual occidentales alrededor de Pasolini si al analizar su obra y vida desplazamos nuestra mirada hacia una perspectiva antirracista?

A menudo, el carácter orientalista y exótico del poeta parece ser algo espinoso en los estudios pasolinianos. De repente este aspecto se convierte en algo de insuficiente importancia en el mundo académico. Un tabú que, si profundizamos en su lectura, refleja los vacíos de la historiografía italiana que, en gran medida y después de la Segunda Guerra Mundial, han procurado excluir el pasado colonial de la historia nacional. Solo a partir de los últimos diez años ha habido un creciente interés en la historia del colonialismo italiano desde una perspectiva poscolonial (Mezzadra, 2004; Giuliani y Longobardi-Diop, 2013; Grecchi y Gravano 2016). Sin embargo, muchos de sus aspectos permanecen inexplorados, particularmente aquellos relacionados con la historia de la cultura. En este sentido, el análisis de la obra y vida pasoliniana nos sirve para reconstruir una genealogía cultural personal y colectiva que atraviesa el contexto y la historia del territorio italiano y europeo. Esta genealogía es también parte de una memoria que está vinculada indiscutiblemente con el mundo y con la historia de las colonias. La historia oficial italiana así como el testimonio pasoliniano son narraciones que se han construido simultáneamente y que, a la vez, no se pueden separar de la historia de los/ las "Otros/as" internos/as al territorio italiano, como de los/las "Otros/as" no occidentales. Si pensamos en la construcción de esta historia desde una mirada poscolonial nos movemos hacia una comprensión multilateral y plural de nuestro pasado y nuestro presente.

El objetivo de esta contribución es, por una parte, situar la figura pasoliniana en el contexto 
histórico italiano contemporáneo, además de analizar su especial interés en la creación de archivos de memoria colectiva, y, por otra, visibilizar el aspecto más orientalista de su obra a irúvés del análisis de algunos textos literarios y documentales que el autor hizo en la India y en el África nororiental.

El análisis de la forma en que Pasolini generó archivos de memoria a través de su producción es una cuestión muy compleja en su obra. A través de las metodologías etnográficas y de su visión personal de la realidad de aquellos años, el intelectual italiano quería representar un imaginario social y cultural en contraste con aquel propuesto por la sociedad neocapitalista y consumista, que cree estar construida como mera página en blanco, sin vínculos con la historia. Frente a esto el autor tenía una exigencia constante de proteger la cultura pre-industrial (del mundo campesino friulano, del subproletariado romano y del "Tercer Mundo") oponiendo este imaginario de lo que él consideraba que era la cultura "arcaica" en oposición a la sociedad capitalista. Pero si leemos su obra desde una perspectiva poscolonial es fundamental preguntarse ¿qué representa el imaginario subjetivo del poeta? ¿qué relaciones profundas con la herencia cultural colonialista está cargado su imaginario de la otredad? Y finalmente ¿el autor consiguió producir archivos que se alejaron realmente del imaginario dominante occidental? Si intentamos interrogarnos sobre los vacíos históricos que se han dado en respecto al llegado colonial italiano y examinamos la producción pasoliniana desde este enfoque podemos decir que la construcción de la identidad fascista basada declaradamente en aspectos racistas y de la izquierda italiana basada en un asistencialismo solidario encuentran puntos en común en su hegemonía hacia "los Otros". Hablar de orientalismo o exotismo en referencia a la obra de Pasolini puede incomodar a muchos/as estudiosos/as y activistas progresistas pasolinianos. Mi intención no es deshacer la figura de Pasolini, al cual le reconozco una importante lucha radical de autodeterminación antifascista; sino más bien detectar y visibilizar aquellos procesos estructurales de dominación, encarnados y a veces inconscientes, que se reproducen y se repiten en la construcción hacia la otredad. Revelar estas dinámicas de poder también en la obra de Pasolini nos sirve para cuestionar nuestras referencias culturales, tener más conciencia y evitar posible repeticiones. En este aspecto, algunos textos narrativos y documentales hechos en "forma de apuntes" realizados en sus experiencias de viaje en la India y en el Cuerno de África resultan ser documentos importantes a la hora de estudiar la relación del intelectual con la otredad. 


\section{L'ODORE DELL'INDIA: ESTEREOTIPOS, NORMALIZACIÓN DEL “OTRO” Y AHISTORICIDAD EN EL DIARIO DE VIAJE}

Según el antropólogo italiano Alberto Sobrero, Pasolini no recibió una formación académica antropológica. Sin embargo, en su proceso creativo utilizó prácticas de investigación típicas de la antropología y la etnografía como: la investigación de campo, la observación participante, la necesidad de los informadores o ayudantes nativos, la comparación, la interpretación y la formulación (Sobrero, 2015). Si analizamos la participación activa del cineasta (como actor) y la estrategia de la alusión en la narrativa de sus películas, podemos afirmar que el autor deconstruye el método antropológico objetivo moderno que fundaba su legitimidad científica en una narración distante e impersonal del texto escrito o cinematográfico, introduciendo, en su lugar, la importancia de la presencia subjetiva tanto del autor como del espectador. Aun así, los instrumentos etnográficos que Pasolini integra en su metodología de investigación están inevitablemente cargados de una herencia colonial, ya que, el surgimiento de la etnografía moderna en Italia ocurre en paralelo a la empresa colonial italiana en el Cuerno de África a partir de los principios del siglo XX. Lo que quiere demostrar es que la documentación que se conseguía en la época colonial -con el uso de estos instrumentos- y que también Pasolini consiguió en su época, no podía ser científicamente neutra y políticamente neutral ya que se llevaba a cabo en un contexto histórico y colonial específico, atravesado por las miradas y el control del poder político y religioso occidental. En su ensayo Orientalismo el crítico y teórico literario palestino Edward Said afirma que ser europeos en Oriente implica siempre tener conciencia de estar separados y ser distintos a la realidad circundante (Said, 1999). Las preguntas que él nos propone en su ensayo son sobre el por qué se quiere ir a Oriente, por qué los occidentales se dirigen a Oriente y cuáles son las intenciones del ir a Oriente, incluso cuando no nos movemos de Europa o de Occidente. Según Said, para identificar un texto orientalista es necesario prestar atención a los estilos, las figuras retóricas, los contextos, los trucos narrativos, las circunstancias históricas y sociales (o no), la exactitud de la representación o su fidelidad respecto a la realidad original (Said, 1999). Por otro lado, el antropólogo, historiador y crítico literario americano James Clifford sostiene que además de las inclinaciones culturales y políticas del creador, los textos antropológicos son determinados por diferentes variables tales como el contexto, la historia, los géneros literarios elegidos (ensayos, narrativa, cuaderno de viaje o documentales), las instituciones pertenecientes del autor y el destino al cual va dirigido el trabajo creativo-etnográfico (Clifford, 1997). Por estos motivos tanto para Clifford como para Said, en el discurso cultural y en los intercambios interculturales, en moverse no son las "verdades" sino las representaciones (Said, 1999). Siguiendo estas líneas teóricas, la relación que se instaura entre la alteridad y la mirada del narrador o director determinan uno de los elementos típicos que estructuran el relato de viaje. Se trata de una cuestión de poder, de dominación, de formas de hegemonía diversas y complejas; las mismas que encontramos en la relación de poder que se instaura entre Oriente y Occidente (Said, 1999).

Las analogías entre las prácticas pasolinianas y las prácticas etnográficas en las actividades previas de investigación -como la investigación de campo- nos permiten analizar el carácter más orientalista contenido en la obra del poeta. Su primer viaje fuera del continente europeo fue en 1961 donde -junto a los escritores y amigos Elsa Morante y Alberto Moravia- viajó a Kenia. Después de este primer viaje siguieron muchos otros donde viajó a la India, Sudán, Zanzíbar, Ghana, Guinea, Uganda, Tanzania, Senegal, Costa de Marfil, Malí, Burkina Faso y Eritrea entre 1961 y 1973 (Naldini, 1989). En la frecuencia de los viajes se puede observar cómo Pasolini 
encarna la figura del intelectual-viajero que desde la segunda mitad de los años 50 prevalecía en Italia como consecuencia directa del auge económico de la posguerra. Este boom económico influyó la forma en que se viajaba, acelerando y facilitando el comercio entre los países. El proceso de descolonización se entremezclaba al neocolonialismo económico que abrió nuevas fronteras especialmente a los viajeros occidentales. Este cambio de perspectiva será significativo en las prácticas pasolinianas ya que le servirá para imaginarse más allá de las fronteras nacionales italianas. La transición fuera de las fronteras italianas le dará la posibilidad de aprender nuevas formas de expresión y profundizar disciplinas como la antropología, la sociología y la etnografía, pero, sobre todo, lo acercará a la otredad no europea, que será a partir de ese momento el banco de pruebas que cuestionará su identidad, donde el autor experimentará un sentimiento de desorientación que afrontará con algunas típicas estrategias orientalistas de normalización y familiarización de lo desconocido (Bhabha, 2002). Por el confluir de todos estos factores se podría considerar al autor como uno de los pocos intelectuales italianos que, después de la Segunda Guerra Mundial y de la consiguiente pérdida del régimen Fascista de sus colonias africanas, se acercó de manera continua y significativa al colonialismo italiano en el Cuerno de África. Los textos sobre sus experiencias en India L'odore dell'India (1962) y en Eritrea La grazia degli Eritrei o Post-scriptum a "La grazia degli Eritrei" (1968) y sus diferentes películas y documentales rodados en territorios indios y africanos en los años 60 y 70 proporcionan herramientas preciosas que revelan la continuidad subyacente entre el colonialismo prefascista, el fascismo y las representaciones poscoloniales del África colonial italiana (Trento, 2010).

Según Said, en los siglos XIX y XX el orientalismo tuvo una difusión más amplia debido a que las distancias geográficas reales e imaginarias se habían reducido, ya que la relación entre Oriente y Occidente se vio cada vez más bajo el signo de una expansión europea imparable en busca de nuevos mercados, recursos y colonias y, finalmente, porque el orientalismo mismo había completado su metamorfosis desde el discurso erudito hacia la institución imperial (Said, 1999). Con el fin de la Segunda Guerra Mundial y el surgimiento de las nuevas políticas de los países africanos e indios recientemente independizados despertó el interés -por parte de muchos intelectuales italianos- de viajar fuera de las fronteras del propio país con la consecuente disposición en la producción de una literatura de viajes. Muchos de los textos escritos en aquellos años nacieron como textos periodísticos publicados en periódicos nacionales. Conforme a los movimientos intelectuales en boga en los años 50 y 60, en 1961 Pier Paolo Pasolini viaja a la India con Alberto Moravia. Los dos poetas y amigos son enviados por dos de los principales periódicos nacionales el Corriere della Sera e II Giorno para relatar un informe detallado sobre un país que aún era poco conocido en Italia. A partir de este viaje se publicaron dos libros; Una idea dell'India (1961) de Moravia y L'odore dell'India (1962) de Pasolini. La narración del viaje realizado por los dos intelectuales hace visibles dos posiciones muy diferentes entre sí que describen claramente dos metodologías poéticas y antropológicas relacionadas con una aproximación típicamente occidental a la alteridad. Por ello, podemos afirmar que el carácter que acomuna a los dos intelectuales italianos será el aspecto orientalista de sus diferentes representaciones que se desarrollará en las figuras retóricas del primitivo y del bárbaro cultural.

Las diferentes metodologías de acercamiento a la escritura generaron dos textos diversos en estilo y en estructura. Moravia escribirá artículos y ensayos para contar una idea de la India impulsada por aspiraciones científicas y periodísticas que, a menudo, escribirá a la vuelta de su viaje para no dejarse influir por los aspectos emocionales. De esta manera, Moravia se presentará como un escritor independiente, un intelectual que analizó los "Otros" desde arriba, donde su lectura particular se convierte en universal. Su manera de entender a los indios fue 
desde la distancia física alejada. Desde la distancia de un coche, percibiendo el coche como un lugar protegido, que le permitió ver sin ser visto y analizar al otro sin conocerlo. Por otro lado, Pasolini escribirá un texto en directo llevando -durante el viaje- un cuaderno en el que apuntar su visión personal, sentimental y sensorial de la India. El cuaderno de Pasolini se convertirá así en el típico diario de viaje utilizado por muchos etnógrafos en las investigaciones in situ. En este diario observamos como ingenuamente el poeta pensó que eligiendo la forma exclusiva de la experiencia personal podía evitar una imagen abstracta y estereotipada de la India centrando la experiencia más en el encuentro con los indios que en la India como realidad territorial. Para Pasolini, a diferencia de Moravia, caminar será la manera que le permitirá conocer la India de una forma más directa, involucrándose físicamente en el contexto sin ninguna mediación.

Los dos textos tan diferentes como iguales, analizados desde una perspectiva antropológica, son testimonio de la crisis de la cultura occidental moderna. Alberto Moravia y Pier Paolo Pasolini pueden considerarse dos Autores-Antropólogos que nos hacen espejo de dos prácticas etnográficas diferentes que se refieren respectivamente a dos líneas de pensamiento occidental: por un lado, la antropología moderna y, por otro, la antropología deconstructivista. La comparación de estos dos textos nos muestra la lógica de la narración occidental en su doble cara: universal frente a particular, mente y vísceras, razón e instinto, objetivo y subjetivo. En el prefacio del libro de Moravia, Tonino Tornitore escribe:

"Con Moravia hay siempre la sensación de ver el mundo con el telescopio y el detalle, la historia es siempre la clavija o el microcosmos de un panorama; con Pasolini miramos con el microscopio y se nota, detrás del observador que describe, el hombre que siente y que trae todo un universo en un minuto particular y subjetivo". (Tornitore, 2007, p.16)

Esta lógica se caracteriza por un binomio constante que crea discursividades culturales aparentemente diferentes, pero complementarias en la misma dialéctica etnocéntrica. Tenemos que recordar que en el contexto no occidental Pasolini es un extranjero, europeo, con condiciones económicas acomodadas. Desde esta posición de fuerza describe, interpreta y explica al lector italiano la esencia de los otros. Los relatos de viaje de Pasolini, tanto en su primera narración L'odore dell'India como en muchas otras obras, se pueden considerar el producto de la cultura de su sociedad de origen, sus estereotipos y sus prejuicios en contra de otras culturas. En la práctica de escritura, Pasolini asume un papel de interprete de las culturas $y$, en cierto modo, realiza una traducción -de las otras culturas- a la cultura de que pertenece y de acuerdo a los cánones de ésta.

En la obra pasoliniana encontramos a menudo nociones como la diversidad, el estereotipo, la ahistoricidad, la normalización del "Otro" y la desorientación del autor. Según Bhabha, estos conceptos son elementos típicos que califican los textos (en nuestro caso pasolinianos) como textos de carácter orientalista (Bhabha, 2002). Para Said, estos aspectos toman forma a través de las estrategias retóricas que tienden a describir el "Otro" como irracional, sin historia, primitivo, incapaz de explicar su comportamiento si no es a través de las palabras occidentales (Said, 1999). Siguiendo la investigación sobre el orientalismo en Pasolini de Caminati, si analizamos el texto L'odore dell'India desde el primer paseo del poeta en tierra india, podemos encontrar estas referencias orientalistas:

“El mar es tranquilo, no muestra signo de presencia. A lo largo del parapeto que lo contiene hay coches aparcados y, junto a ellos, unas criaturas maravillosas, sin raíces, sin sentido, llenas de significadas dudas e inquietantes, dotados de un poderoso 
encanto, que son los primeros indios de una experiencia que quiere ser exclusiva como la mía”. (Pasolini, 1998, p.1199)

"Los indios en este momento son un gran pueblo de atontados y vacilantes: cómo aquellas personas que han vivido durante mucho tiempo en la oscuridad y de repente son sacados a la luz". (Pasolini 1998, p.1258)

Ya desde estos primeros fragmentos del texto, las representaciones pasolinianas ofrecen un retrato de los indios como sujetos sin historia y "sin raíces", una visión subjetiva y discutible en la que, a menudo, no hay correspondencia real con el país visitado. Debido a esto, el relato de 1961 es considerado -por muchos críticos- un texto orientalista y fácilmente reprochable desde una perspectiva crítica en clave poscolonial (Riva y Parussa, 1997, Caminati, 2010).

Como nos señala Said, una actitud que se repite en la literatura de viajes es la comparación entre lo nuevo y lo conocido que se da por el estado de desorientación de quien se acerca a la otredad (Said, 1999). A través de esta operación se controla la angustia por el incognito relacionándola a algo considerado familiar, pero, de la misma manera, se actúa una distorsión del encuentro con lo que es diferente. "El Otro" viene relacionado a categorías que pueden describirlo solamente por similitud a algo familiar o por diferencia. Como muchos intelectuales que se han confrontado con la otredad, Pasolini -a modo de resistencia a este estado emocional de desorientación- intentará adaptar sus referencias occidentales a la nueva situación utilizando aspectos típicamente orientalistas como la creación de una simbología del "diferente". Según Said, esta simbología pone en contraposición la idea de lo que es familiar (Europa, Occidente y "nosotros") con lo que es insólito (Oriente, Este, "ellos"), es decir, aquella idea colectiva a través de la cual contrastar el "nosotros" (europeos) a los "Otros" (no europeos) normaliza el "Otro" desconocido al ponerse bajo cánones occidentalmente reconocibles que el viajero/narrador utiliza para orientarse en el nuevo contexto (Said, 1999). En este sentido, la comparación se convierte en una estrategia orientalista que sirve para descifrar, clasificar, controlar y, por lo tanto, poseer una realidad desconocida. En el texto/diario pasoliniano se pueden extraer numerosas similitudes a través de las cuales el autor interpreta la realidad de la India en relación con las situaciones y contextos familiares a él buscando occidentalizar la realidad de India. Esto correspondería -de acuerdo con las aportaciones críticas de Edward Said- a la necesidad de recordar realidades habituales para hacer frente a la amenaza de desorientación cultural y psicológicas causada por el enfrentamiento con la alteridad.

"Así que llegamos bajo la Puerta de la India. (...) se oye un canto: son dos, tres voces que
cantan juntos, fuertes, constantes y fervientes. El tono, el significado, la sencillez son los
de cualquier canto de jóvenes que se puede escuchar en Italia o en Europa, pero estos
son indios, la melodía es india". (Pasolini, 1998, p.1201)

Todas estas reacciones de desorientación hacia el/lo "Otro" son a la vez defensivas y conservadoras. Según Said (1999), "para controlar la otredad se modifican las amenazas del desconocido, se imponen valores familiares y -con el fin de atenuar la presión mental- se actúa una discriminación entre elementos originales y otros que se consideran, en el fondo, repeticiones" (p. 65).

Como nos señala el teórico del cine Luca Caminati en su análisis sobre el poeta, Pasolini era consciente de la tradición orientalista europea moderna y por este motivo no quería hablar de la India como los escritores orientalistas. Pero, para lograr no serlo "intentó reprimir forzadamente 
su memoria del pasado para conseguir sentirse, ingenuamente, como el primero en contar al lector italiano la experiencia de la India" (Caminati, 2010, p.22).

“Para mí, que siento la vida de otro continente como otra vida, sin relaciones con la que
conozco, casi autónoma, con otras leyes internas, vírgenes" (Pasolini, 1998, p.1201).

Según Caminati "el primer viaje de Pasolini no será una aventura hacia lo desconocido, sino, más bien, un intento de normalizar lo que no conoce, lo que no reconoce. Por eso su empeño en mirar el mundo indio con nuevos ojos, ser percibido como inocente (porque no agravado del peso de la tradición orientalista) y reprimir la memoria orientalista, se revela desde las primeras páginas un fracaso" (Caminati, 2010, p.21).

\section{LO ARCAICO, EL “BUEN SALVAJE" Y LO EXótICO EN EL CINE-DOCUMENTAL PASOLINIANO}

En los años 60 Pasolini se encuentra en una profunda crisis política, ideológica y estética. Entre el 1957 y el 1961 termina de escribir Le ceneri di Gramsci (1957) y comienza el rodaje de su primera película "Accattone" (1961). Este cambio de dirección de la literatura al cine vino determinada por un fuerte deseo del poeta de hacer frente a las realidades de su presente obteniendo un mayor impacto en el público italiano que en aquellos años estaba abandonando la lectura de novelas por una gratificación más inmediata aportada por el cine. Esta transición no va a presentarse simplemente como una crisis de estilo o de paso a otros medios de expresión, sino que será una verdadera crisis filosófica que el autor va a documentar en sus textos teóricos recogidos, sobre todo, en Empirismo eretico (1972). Desde aquí entenderá la importancia y la necesidad de profundizar y enfrentarse a las nuevas técnicas y disciplinas analíticas que se estaban desarrollando en aquellos años como el estructuralismo, la semiótica y la antropología, una serie de técnicas y disciplinas que hasta entonces habían sido ignoradas por la cultura idealista y por la izquierda oficial. Pero, además, siente la necesidad de ir más allá de la abstracción simbólica del lenguaje escrito-hablado con el fin de vivir a través del cine una experiencia más tangible y física de la realidad.

Según el poeta, el cine conecta directamente con la vida, el lenguaje vivo de la acción, la presencia física, la apariencia, el comportamiento, las costumbres, los rituales y finalmente también con la lengua escrito-hablada. Mientras en sus primeras novelas romanas "Ragazzi di vita" (1955) y "Una vita violenta" (1959) el problema de la representación de la realidad se resolvió en una imitación de la jerga romana, con el cine el autor descubre la posibilidad de narrar su entorno a través de las cosas, la fisicidad de las personas, los gestos y los territorios por lo que cada elemento es lo que es, sin la necesidad de una traducción desde el lenguaje oral hacia el lenguaje cinematográfico.

En sus documentales utiliza diversas estrategias que le servirán para acercar y comparar diferentes metodologías antropológicas (moderna y postmoderna), diferentes contextos geopolíticos (occidental y no occidental), diferentes periodos históricos (contemporáneo y arcaico) y diferentes estilos estéticos (documental y narrativo). Emplea en su narrativa tanto la construcción del mito del "buen salvaje" como la búsqueda de una "lengua primitiva e infantil" para recuperar, ilusoriamente, una idea de pureza y de esperanza que proyectaba en "Ios Otros" como sujetos simbólicos no contaminados por la degradación de la cultura industrializada moderna. 
El primitivismo, en la obra pasoliniana, puede ser leído como un sentimiento de nostalgia de una condición pre-civilizada, en el cual proyectar no sólo una inocencia que la modernidad ha violado y contaminado, sino también la posibilidad de experimentación de nuevas formas estéticas por parte del autor donde proyectar su imaginario exótico como símbolo y forma de vida que le recordaba una época ahistórica arcaica. La fascinación de Pasolini por el "bárbaro" es presente ya desde su producción literaria en el Friuli como en las periferias romanas. Pero, será con el cine, sobre todo, después de sus viajes por África e India y su interés a la mitología griega cuando este efecto se hará más evidente y -gracias a las imágenes- tomará una forma más tangible.

Si consideramos la importancia del componente antropológico en la obra pasoliniana, no podemos prescindir del aspecto alegórico de lo arcaico y de lo exótico que encontramos en su imaginario. Según Clifford, todos los textos etnográficos son inevitablemente alegóricos, es decir, construcciones narrativas no objetivas, sino más bien subjetivas. Con esta afirmación el antropólogo no quiere sostener que los documentos antropológicos no sean el resultado de experiencias reales, sino, más bien, que estas narraciones no pueden ser consideradas objetivas y universales, ya que son fruto de construcciones culturales que dependen de la cultura de proveniencia de quien escribe, su formación, sus intenciones y la finalidad del texto escrito, una serie de características subjetivas que condicionan los relatos en su estructura.
(...) la etnología es entendida como una práctica que se caracteriza por narraciones. Las narraciones, encarnadas en informes escritos, describen eventos culturales reales y proporcionan afirmaciones morales ideológicas y cosmológicas. La escritura etnográfica es alegórica por el contenido (lo que dice acerca de las culturas y de sus historias) y por la forma (el modo de construir el texto). (Clifford, 2006, p.135)

En otras palabras, para el crítico americano enunciar que un texto es alegórico, no significa que el texto sea incorrecto, sino, más bien, que el texto ha sido construido por el etnógrafo y que por este motivo tiene una visión parcial de la realidad, ya que se basa en un proceso de selección y exclusión previa -hecha por el autor- de los elementos de la realidad.

Hasta mitad del siglo XX la antropología moderna estuvo influida por las corrientes culturales del positivismo, el realismo y el romanticismo que compartían entre ellas el rechazo de la retórica y la supuesta abstracción alegórica (ya que las consideraban una violación de los cánones de la ciencia empírica). Conforme a las argumentaciones de Clifford, el focalizarnos en la alegoría nos sirve para desviar la atención desde la creencia de cientificidad de los textos antropológicos hacia una construcción narrativa de la representación cultural más heterogénea. Considerar el carácter alegórico de un texto etnográfico nos sirve para visibilizar las diferentes historias paralelas construidas durante el proceso de representación. Es decir, a partir de las observaciones de Clifford podemos analizar tanto la supuesta historia objetiva generada por el etnógrafo/documentalista como la historia misma de quién escribe el relato etnográfico. Según el crítico americano, estas historias siempre han coexistido en el relato antropológico, solo que la antropología académica moderna pensó que era oportuno ocultar el papel del antropólogo como escritor, considerándolo un sujeto neutro capaz de generar un análisis válido para todos.

Con la obra de James Clifford la antropología entra en su fase posmoderna y deconstruccionista. Sus análisis destacan la importancia de la alegoría al ser una práctica persistente dentro los textos etnográficos donde una historia inventada está en relación constante con otras estructuras de ideas o eventos. Desde esta perspectiva, los textos antropológicos pueden ser leídos como 
metarrelatos ${ }^{1}$ literarios o cinematográficos, es decir, el interés del autor está en narrar el proceso narrativo elegido por el autor en sí mismo. De igual manera, el metarrelato (o narrativa de segundo grado) se obtiene, en el cine, cuando dentro del texto (película en este caso) se cuenta una historia dentro de la historia. Si consideramos la importancia de la perspectiva subjetiva introducida por Clifford, pensar en los textos antropológicos como metarrelatos nos permite analizar los textos o documentos en sus diferentes niveles narrativos. Aun así, la idea de metarrelato en el texto antropológico puede correr el riesgo de leerse también como una explicación global y totalizante. El desplazamiento de la atención que Clifford hace desde la narración (texto escrito) hacia el narrador (subjetividad del autor) nos ofrece, por una parte, las herramientas para analizar el texto etnográfico no como un relato universal, sino más bien desde una perspectiva subjetiva (que, en la mayoría de los casos, pertenece a un contexto occidental) y, por otra, puede volver a direccionar los discursos críticos hacia una forma extrema de etnocentrismo, que, paradójicamente, vuelve a aparecer en una de las más relativistas tesis contemporáneas.

La fórmula del cine por apuntes o de la película "por hacer" pasoliniana permite al autor tener a! iertos diferentes lenguajes y niéveles narrativos que él utiliza, sobre todo, para encontrar conexiones ideológicas y estéticas con la otredad. Desde este punto de vista, el proceso de construcción del relato pasoliniano tiene puntos en común con las reflexiones enunciadas por James Clifford. La similitud es tal que Pasolini era consciente de la construcción cultural incorporada por el autor del texto escrito y cinematográfico de las personas representadas en él a través de los comportamientos, las acciones, los objetos y los paisajes de la realidad, así que prestaba mucha atención en subrayar la importancia del compromiso ético e ideológico del autor en la realización de un texto o de un documental: “(...) la primera elección de las imágenes posibles no puede no ser determinada por la visión ideológica y poética de la realidad que tiene el director en ese momento" (Pasolini, 1972, p.174). Aun así, tener un discurso éticamente comprometido se vuelve complicado desde el momento que se introduce la relación con el "Otro". Enfocarnos en el carácter alegórico de la obra pasoliniana nos permite centrarnos en algunos aspectos relacionados con la representación cultural de la otredad contenida tanto en sus textos (novelas, poesías o ensayos) como en sus películas o documentales. Nuestro interés se centra principalmente en conceptos como el "buen salvaje», lo arcaico y la representación exótica de la otredad, una serie de nociones que están interrelacionadas entre sí y en las que la representación del "Otro" está determinada por una construcción alegórica que el autor elabora en su relato.

En la obra del poeta el sentimiento hacia el tiempo se desarrolla en una forma de persistencia vinculada al pasado y de distanciamiento del presente. En este sentido, la búsqueda e idealización de lo arcaico y del primitivo -utilizada por Pasolini como fórmula de resistencia en contra a la modernidad- dependía, por una parte, de un sentimiento de nostalgia por el pasado y, por otra, de la búsqueda de otros territorios lejanos a la Italia de los años 60 y 70 . Desde una perspectiva política e ideológica, el "Otro" es para Pasolini el lugar del redescubrimiento de la pre-modernidad, de la época antes de la alienación capitalista donde la industrialización y el

1 En este punto de la investigación nos referimos al significado de metarrelatos o metanarrativas como conceptos vinculados a la literatura y al cine, donde -además de desarrollar la historia del texto o de la película- se expresa la tendencia del autor o director a querer describir el proceso de escritura de la novela o de la película misma. El término metarrelato es utilizado por Jean-François Lyotard en su ensayo titulado "La condición Postmoderna", con un sentido diferente al utilizado por la crítica literaria. Para él el metarrelato no tiene que ver con narración ficticia literaria sino más bien con discursos legitimadores a nivel ideológico, social, político y científico. En este sentido, Lyotard considera los metarrelatos como "grandes relatos" asumidos como discursos totalizantes y multiabarcadores. Muchos críticos creen que la cuestión posmoderna de crítica al metarrelato propuesta da Lyotard puede ser vista como una construcción narrativa en sí misma. 
consumismo no habían afectado los valores de la cultura de la tierra. Caminati opina que, desde un punto de vista estético y personal, el "Otro" va a convertirse en la posibilidad de una nueva libertad estilística y erótica donde encontrará nuevas caras, nuevos paisajes y nuevas historias que contar (Caminati, 2010).

El cine documental pasoliniano en forma de "apuntes" es una fórmula abierta, un borrador que hibrida el documental de investigación con la película de ficción. Este género experimental será utilizado por el director como un "guion visual" donde el autor mezcla rodajes in situ con el relato de una posible película futura "por hacer" que Pasolini imaginaba en los lugares que iba filmando. De esta manera, las películas resultantes fueron metarrelatos, borradores visuales para una presunta película "por hacer", o como la define el mismo autor "una película para una película por hacer" (un film per un film da farsi). El nuevo estilo de documental en "apuntes" será descubierto accidentalmente durante las inspecciones in situ que Pasolini realizó en Palestina en busca de posibles lugares donde rodar la película // Vangelo secondo Matteo (1964). La experiencia de las inspecciones en Palestina van a dar la posibilidad a Pasolini de experimentar una forma híbrida entre el documental tradicional y el documental de creación.

El lenguaje discursivo del cine por apuntes se caracteriza por mezclar el imaginario visual con relatos narrativos. Esta fórmula cinematográfica se aproxima a las notas escritas en la fase técnica de investigación de campo, práctica que utilizaron varios directores neorrealistas que rechazaban el set cinematográfico en favor de filmaciones al aire libre. Para Pasolini esta fórmula se convierte en un diario de viaje visual que le permite hacer coincidir el tiempo de la experiencia física (compartida en tiempo real con sus compañeros de rodaje/viaje) con el tiempo dilatado y solitario de la documentación etnográfica hecha a través de la escritura. Además, con la estrategia de los apuntes demuestra la voluntad de enfrentarse a los problemas y metodologías antropológicas no sólo en sus prácticas más tradicionales y objetivas de reconstrucción de la realidad sino a través de la introducción de su voz en off en fase de montaje para añadir un texto de carácter narrativo que explica el proyecto fílmico que hará en otro momento.

En el proceso de creación de los documentales en apuntes, la historia narrada a través de la voz en off tiene la misma función que el guión en una película, es decir, que tanto la lengua escrita del guion como la voz en off del documental anticipan al que lee/ve el advenimiento de otro proyecto cinematográfico (película futura por hacer). Como afirma el crítico literario Marco Bazzocchi, Pasolini:

\footnotetext{
"Quiere demostrar que un guión es una forma de expresión que le permite expresar simultáneamente dos niveles diferentes de conciencia: una racional y otra irracional, una intelectual y una visual, una conectada a los códigos de escritura y la otra conectada al código de la realidad. La palabra del guión pertenece a «dos lenguas con estructuras diferentes» y es, en sí mismo, una estructura en movimiento". (Bazzocchi, 2013, p.57)
}

De esta manera, los guiones como los documentales en apuntes pueden ser considerados como "obras abiertas" (Eco, 1962) que piden al lector/espectador que participe en el dialogo con el autor, que complete el proceso creativo mientras percibe estéticamente el guion. Y, en este sentido, los documentales por apuntes encajan estilística y conceptualmente en una zona intermedia entre cuaderno de viaje, guion y documental etnográfico. En esta zona intermedia es donde el autor propone un espacio de encuentro que se traduce en un espacio estético, ideológico y técnico mítico. 
Si analizamos la película, considerando el carácter experimental de su práctica cinematográfica del "por hacer", nos damos cuenta de que el lugar intermedio que el autor propone al espectador nos permite leer las diferentes realidades representadas en ella. A través de esta fórmula, Pasolini crea lo que el antropólogo hindú-norteamericano Homi Bhabha denomina "tercer espacio" (Bhabha, 2002). Este espacio entremedio -que el documental en apuntes genera- nos va a permitir hacer asociaciones entre algunas divisiones binarias con las cuales se suelen construir las identidades. Según Caminati, en el tercer lugar -el de los "apuntes"- nace la posibilidad de que sucedan una serie de encuentros, desencuentros, conflictos recurrentes, negociaciones o hibridaciones culturales que mantienen diferentes concepciones de la vida y visiones del mundo (Caminati, 2010). Es, también, un lugar que contiene la experiencia de las relaciones físicas y materiales y la experiencia imaginada de las representaciones mentales. Concretamente, en la fórmula por apuntes de la realidad india y africana -que se visualiza a través de las imágenes, de los paisajes, de la arquitectura y de los rostros de los nativos- se sobrepone la realidad del imaginario pasoliniano proyectada en sus filmaciones de la India y de África. Estas caras "pasolinianas" tan típicas de su cinematografía "son, de hecho, las caras reales de la India y de África y, al mismo tiempo, la proyección de la mirada del director sobre estos territorios, el producto de su visión preconcebida y mediada" (Caminati, p. 71, 2010). Es muy común escuchar decir que la fisionomía de algunos chicos tiene una cara típica pasoliniana. En esta proyección del imaginario subjetivo del autor en "los Otros" se gestará un verdadero archivo de imágenes que definirá su imaginario personal, lo convertirá en algo característico de su estética y "patentará" una especie de firma de autor. Aunque, también, se podría calificar como una apropiación visual que convierte la otredad en espejo del autor.

Con el proyecto Appunti per un poema sul Terzo Mondo (1968) la intención de Pasolini era mostrar el nacimiento de una conciencia política de los diversos países del "Tercer Mundo" que según él -en aquellos años- estaban sometidos y divididos entre el modelo neocapitalista occidental y el mundo tradicional, arcaico, mítico, pre-industrial y pre-burgués. Formalmente pensaba utilizar la fórmula de "una película sobre una película por hacer" en la cual se alternaban entrevistas, inspecciones in situ y partes de narrativas. La redacción del proyecto se dividía en cinco episodios que se rodarían en diferentes países del "Tercer Mundo" (India, África, Países árabes, guetos negros norteamericanos y las guerrillas en América Latina). En cada episodio Pasolini tenía pensado desarrollar un tema específico que hacía referencia a la actualidad del sitio donde se hubiera rodado. Finalmente, el proyecto completo no se realizó a causa de los elevados costes de producción. El único episodio que se llevó a cabo fue el rodado en África. En estos años, el autor pensó en ambientar la tragedia griega de Esquilo, la Orestiade, en el África poscolonial (concretamente en Tanzania y Uganda) y de esta idea nació la película Appunti per un' Orestiade africana (1970). El mito de Orestes debía interpretarse como una tragedia que explicara la transición de un estado arcaico y primitivo a uno formalmente democrático. Para su versión de la Orestiade, Pasolini afirmó que el significado político de la tragedia de Esquilo era lo más fascinante que podía encontrarse en un texto clásico, en cuanto que el autor griego hacia un uso ideológico y político de la poesía. Por ello, la lectura de la Orestiade africana pretendía ser una lectura política. Pasolini recupera el mito griego como un elemento común transnacional adaptable en lugares y tiempos diferentes. Para él, la Orestiade representa una herramienta narrativa que le permite hacer una comparación entre diferentes culturas y diferentes épocas. Mediante la puesta en escena de la tragedia griega en África, el autor quiere hacer una comparación entre el proceso de transición desde una sociedad primitiva -dominada por los sentimientos primordiales, obscuros e irracionales, representado por las Furias- a una nueva comunidad democrática guiada por Atenas (diosa de la Razón) y fundada sobre modernas 
ir.stituciones humanas como el tribunal, la asamblea y el sufragio. De esta forma, la reflexión sobre la Orestíade se convierte en una metáfora sobre la sociedad contemporánea. Para el autor la idea de hacer una película que lleve el mito de Orestes al África independiente se centra en el paso de la "ciudad tribal africana" a la democracia:

\footnotetext{
"La razón, esencial, profunda es la siguiente: que me parece reconocer algunas similitudes entre la situación de la Orestiade a la del África de hoy, sobre todo, desde el punto de vista de la transformación de las Furias en Euménides. Es decir, me parece que la cultura tribal africana se asemeja a la cultura arcaica griega. Y el descubrimiento que hace Orestes de la democracia llevándola a su propio país -lo que sería Argo en la tragedia- es África en mi película. Es, en cierto sentido, el descubrimiento de la democracia que ha hecho África en estos últimos años". (Pasolini, 2010, p.1181)
}

Si analizamos la adaptación de la Orestiade en el plano visual-fílmico, notamos que ya desde el principio Pasolini necesita recurrir a la figura retórica del oxímoron para conseguir unir culturas y temporalidades diferentes. La película documental Appunti per un' Orestiade africana empieza -durante los créditos iniciales- con la imagen de la traducción italiana de la Orestiade y un mapa geopolítico de África. Tanto estas primeras imágenes del documental como la adaptación en general de la Orestiade nos devuelven a los trucos narrativos orientalistas que desvían la desorientación del autor a una familiarización de la otredad a través del mito griego justificando la comparación a través de la crítica al neocapitalismo que se estaba instaurando también en los territorios africanos. De aquí es importante señalar que Pasolini siempre se dirige a un determinado espectador occidental que entiende el mito griego y los procesos de homologación neocapitalista pero en ningún momento se dirige a un espectador no occidental y cuando lo hace la relación se presenta de cualquier forma desequilibrada y siempre es alguien que, según su opinión, puede entender las lógicas capitalistas que él crítica (véase el ejemplo de las grabaciones de los estudiantes africanos en la Universidad la Sapienza en Roma).

Para Caminati (2010), Pasolini "construye una realidad que tiene en consideración los restos de viejos estereotipos orientalistas" (p.61) -que él utiliza como citaciones para hacer aún más evidente una imagen "real" de los diferentes territorios no occidentales-. Para Donatella Maraschin (2014), Pasolini recupera la "retórica del discurso colonial, reduciendo las culturas tradicionales dentro de los patrones de una sumisión ingenua, proyectándolas idealmente a los inicios (prehistoria) de la sociedad occidental" (p.250). Esto podría ser aplicado a los comentarios verbales (voz en off) que utiliza el director -para introducir sus reflexiones sobre el texto y la realidad de la India y de África- y que reproducen estrategias de estereotipación típicamente orientalistas.

En los documentales por apuntes, la reflexión sobre las cuestiones identitarias surge como resultado del continuo reposicionamiento en la representación del yo del autor. Por un lado, Pasolini mantiene un discurso crítico contra la imposición de los valores de la cultura occidental (que operan una destrucción de los valores tradicionales de otras culturas), impulsando el mundo hacia una homologación global y, por otro, con la inclusión de historias y análisis subjetivas, direcciona el discurso ideológico a una lectura auto-reflexiva a través de la cual emerge la personalidad del propio autor. La otredad actuará en el imaginario pasoliniano como una resistencia a la potencia representativa fascista italiana y a la homologación del poder neocapitalista. Pero, al mismo tiempo, representará la compleja relación entre cultura colonial y neocolonial que viene integrada en el imaginario íntimo pasoliniano a través de una actitud 
orientalista y exótica.

Según las reflexiones de Riva y Parussa, la razón base de las investigaciones antropológicas pasolinianas, literarias y cinematográficas es principalmente la búsqueda del erotismo. Riva y Parussa opinan que, si analizamos los imaginarios eróticos en sus textos y en sus películas, nos damos cuenta de que toda su obra tiene una raíz común homoerótica: "Todos los personajes que animan la literatura y el cine de Pasolini no son más que la manifestación de un deseo erótico y al mismo tiempo un reflejo del autor y de lo que a él le gustaría ser y no es" (Riva y Parussa, 1997, p.257). Por este motivo, son recurrentes figuras como "el chico inocente, los chavales de barrio y todas las encarnaciones de alteridad que se mueven en estos dos extremos, que quieren significar alegóricamente la nostalgia de la juventud y el sueño de virilidad" (Riva y Parussa, 1997, p.257). Para el poeta el conocimiento del "Otro" se da a través del amor que pasa físicamente por los cuerpos. Lo que la antropóloga Giovanna Trento (2007) nomina "Cuerpo Popular" sigue siendo la referencia fundamental del poeta, entendiendo el cuerpo como un icono erótico-poético-político. Para él la única posibilidad de aprender acerca de la otredad es a través de la corporeidad y del eros. A través del cuerpo Pasolini se identifica con los "Otros" y con su mundo. Por ello, el poeta proyecta en el cuerpo del pueblo un imaginario ideal e idealizado que para él representa los valores de gracia, humildad, belleza, atrevimiento y alegría. La corporalidad está presente en todas las experiencias que narra, desde la realidad campesina friulana, pasando por los suburbios de Roma, hasta los viajes a África, Oriente Medio y Asia. Y, a través del cuerpo popular, se relata el encuentro entre el mundo occidental burgués y la cultura popular de los países, por él considerados del "Tercer Mundo". El viaje antropológico del intelectual burgués -que se aleja de su sociedad hacia el "Otro" y portador de una autenticidad perdida- no será una experiencia intelectual abstracta, sino una práctica que le permitirá acercar el espacio impracticable entre quien observa y quien es visto. En la experiencia física, corporal con el "Otro", Pasolini conoce tanto la otra cultura como la propia identidad, que en este encuentro relaja su propia crisis de personalidad. Continuando con el análisis de Riva y Parussa, para el Pasolini de los años 60 y 70 el sujeto homosexual no tiene lugar en la sociedad. El poeta considera que su lugar está fuera de la organización social, entre los que él considera marginados y con los cuales él puede encontrar una forma temporal de colectividad idealizada (Riva y Parussa, 1997). Un imaginario ideal y fugaz que, a los ojos del autor, desaparece en cuanto aquella otredad se integra en los nuevos modelos de sociedad neocapitalista. En este sentido, Pasolini crea un imaginario erótico que no consigue frenar la perdida de la inocencia y el crecimiento del consumismo en los cuerpos populares. Al revés, en el afán de conservar valores de una gracia arcaica y primitiva amplifica este sentimiento de disipación construyendo un imaginario fantasmagórico exotizando/erotizando aún más los cuerpos populares. De este modo, las imágenes proyectadas en la corporeidad de la clase subalterna se convierten en símbolos tanto eróticos como ideológicos.

Además, el instrumento lingüístico -en el que se instaura el cine- es, para Pasolini, un sistema irracional (Pasolini, 1972), ya que la representación de los cuerpos, la mímica y la representación de la realidad en su estado "bruto" son considerados hechos pre-humanos, relacionados a un estado pre-histórico. A través del lenguaje cinematográfico el autor consigue relacionarse con la realidad de una forma más física y corporal.

“Descubrí muy pronto que la expresión cinematográfica me ofreció, debido a su similitud en el plano semiológico con la realidad misma, la posibilidad de alcanzar la vida de una manera más completa. De poseerla, de vivirla mientras la recreaba. El 
cine me permite mantener el contacto con la realidad, un contacto físico, carnal, diría incluso sensual" (Pasolini, 1998, p.1413).

Entre los años 1971 y 1974, Pasolini tiene a menudo la mirada puesta en el pasado que representa a través de los cuerpos subalternos en sus películas. En estos años lleva a cabo la Trilogia della Vita, que incluye II Decamerón (1970), I racconti di Canterbury (1972) e II fiore delle Mille e una notte (1974). Las tres películas están ambientadas en un mundo pre-industrial que representan tres momentos cruciales de la cultura medieval. Cada una reconduce a orígenes, lenguas y culturas diferente donde estas diferencias culturales están representadas por la expresividad física, corporal y sexual de los personajes que actúan en la película. En esta fase de su investigación se hace evidente la representación de la inocencia, la gracia y la instintividad de las clases bajas y los cuerpos subalternos. La atención por estos aspectos está marcada por un cierto esencialismo de las personas y la fetichización de su corporeidad. Homi Bhabha identifica en el mecanismo responsable de la creación psicológica del estereotipo los mismos principios que son la base de la noción de fetichismo propuestos por Freud. Tanto el fetichismo como el estereotipo tienen una estructura común: la ansiedad por lo desconocido y el intento de sustituir la ausencia con imaginarios reconocibles. "El fetichismo es siempre un «juego» u oscilación entre la afirmación arcaica de plenitud/semejanza (...) y la ansiedad que se asocia con la falta y la diferencia" (Bhabha, 2002, p.109). De la misma forma, el objeto exótico funciona como sustituto al que atribuir elementos de un "otro". Según Bhabha, en un contexto colonial el estereotipo o el objeto exótico normaliza la diferencia existente tras el encuentro cultural entre occidental y no occidental, colono y colonizado. Es decir, la sensación de desorientación (vivida como una amenaza) que el occidental experimenta en el encuentro con lo desconocido lo lleva a proyectar sobre lo "otro" un imaginario que le permita normalizar y familiarizar el objeto o sujeto extraño.

En la corporalidad de los "Otros" el poeta proyectará su imaginación erótica, tanto que dirá en una entrevista de 1974 que para él: "el erotismo es la belleza de los chicos del Tercer Mundo, es la relación sexual de ese tipo, violento, emocionante y feliz, que aún sobrevive en el Tercer Mundo (...) Esto es mi eros" (Pasolini, 1999, p.1712). En esta afirmación Pasolini encuentra su erotismo en el carácter violento -vinculado al salvaje- y feliz -relacionado la ingenuidad- que, según él, aún sobrevive en aquellos territorios lejanos y arcaicos del "Tercer Mundo". De esta manera, el cuerpo exótico nunca se toma por lo que es en su materialidad, sino que viene utilizado siempre como soporte de otra cosa, de un imaginario deseado. A diferencia del imaginario orientalista, lo exótico tiene una carga erótica que se relaciona con el deseo y su necesidad consumista. Desde esta perspectiva, el imaginario pasoliniano de los años 70 desarrolla una serie de procesos donde los sentimientos, los cuerpos y las experiencias aparecen transformadas en fetiches estéticos y experiencias de deseo. En este sentido, las representaciones de los cuerpos de la Trilogia se inscriben inexorablemente en un procedimiento hegemónico cultural que produce y sustenta una demanda de consumo de la otredad a partir de la imposición de valores y representaciones de un sujeto y un determinado contexto occidental. Aunque, si Pasolini pensó en la Trilogia a modo de archivo de imágenes de cuerpos populares arcaicos para "proteger" una tipología de cuerpos y comportamientos que según él se estaban perdiendo, estos cuerpos fueron idealizados para convertirlos en símbolos arcaicos. La finalidad de la Trilogia fue, por una parte, conservar un imaginario personal y, por otra, expandir este imaginario para que sea real y así revivirlo de nuevo en vida. Después de la Trilogia se produjeron en Italia numerosas películas pornográficas de serie B. El número de películas fue tan notorio que con ellas se inauguró un género específico del cinema italiano mainstream. Por mucho que Pasolini criticase estas 
películas y no compartiese la sexualidad que representaban, no pudo oponerse a este proceso de liberalización de expresión que él mismo fomentó. En un momento histórico en el que el neocapitalismo apostaba por el consumismo, el deseo se convirtió rápidamente en motor de ganancia. Pasolini tuvo que renegar más tarde de su propio trabajo cuando se dio cuenta de que sus películas estaban acelerando el proceso de perdida de los valores de "inocencia" del cuerpo popular y facilitando aún más la profanación de su imaginario. 


\section{Conclusiones}

El desarrollo económico de los años 50-60 afectará a las ideologías que caracterizaron la Italia de aquellos años, como el marxismo, el catolicismo, etc. y provocará una crisis general en todas estas. Pero, sobre todo, estos cambios marcarán una profunda crisis ética entre el Yo y el Otro. En este ámbito, Pier Paolo Pasolini resulta ser la figura simbólica del Autor-Antropólogo entre modernidad y postmodernidad, colonialismo y poscolonialismo, afectado por una crisis radical del sujeto que escribe y describe la realidad a él contemporánea en una constante contradictoria abnegación de sí mismo y la voluntad de poder.

La aparición de los nuevos movimientos sociales y culturales de los años 60, 70 y 80 en Europa y Norteamérica, como el feminismo, la antropología deconstructivista, los estudios posmodernos y poscoloniales han favorecido diferentes perspectivas de análisis que han complicado y enriquecido el debate sobre la crítica de la representación proporcionada por los documentales y la narrativa de carácter etnográfico. Al analizar las películas etnográficas y los relatos de viaje bajo estos enfoques vemos que las prácticas que los unen se han convertido en un material de debate a la hora de abordar problemas sobre la identidad nacional, étnica y cultural en las representaciones visuales. Estas nuevas perspectivas se proponen romper con el "gran relato", negando la idea de un conocimiento universal y objetivo, que caracterizó la producción cultural y científica positivista moderna. A partir de este momento, la objetividad de las disciplinas científicas -como la antropología- se ven debilitadas por el nuevo relativismo posmoderno y la narrativa de viaje (escrito y filmado) se vuelve uno de los géneros más criticados por estos nuevos enfoques teóricos. Al cine documental se le acusa especialmente de arrastrar algunas prácticas vinculadas a las metodologías antropológicas positivistas modernas basadas en la objetividad del relato filmados. $\mathrm{Si}$, por un lado, la inclusión de la perspectiva subjetiva del director/autor -en la percepción y representación de la alteridad- rompe con la idea de una historia única y objetiva, por otro, esta misma perspectiva tiene el riesgo de centrarse más en la percepción personal del autor que en la otredad, lo cual orienta algunos aspectos del andamiento del relato hacia una visión etnocéntrica.

El estudio de lo exótico nos permite releer la obra del intelectual italiano bajo otra perspectiva que profundiza las inquietudes más íntimas y personales de Pasolini, relacionadas con el deseo erótico y su imaginario exótico. A través de un análisis de algunas estrategias orientalistas utilizadas por el autor frente a la otredad, hemos ido desvelando una recóndita y dramática contradicción identitaria que lo acompañará, hasta sus últimos años de vida.

Hoy Pasolini aparece como Padre Fundador de la Cultura italiana de mitad del 900, alguien considerado lo suficientemente importante como para ser una atracción cultural (y turística) de la Italia contemporánea, alguien que de alguna forma se ha convertido en un fenómeno cultural, en nuevo icono pop representante del imaginario erótico de la sexualidad no heteronormativa. Sin embargo, su imaginario exótico, orientalista de la otredad lo inscribe en un continuum de la retórica de dominación occidental ilustrada. La lectura contemporánea de la obra pasoliniana bajo un enfoque poscolonial nos ha permitido entender retrospectivamente el relato de la historia oficial como su visión particular. En este sentido, este análisis nos ha dado la posibilidad de problematizar la idea del discurso cultural occidental, detectar sus aspectos orientalistas y cuestionar las diferentes representaciones europeas o italianas de la época contemporánea. También, nos ha dado la posibilidad de responsabilizarnos de nuestra propia genealogía cultural y orientar nuestra perspectiva hacia nuevos referentes. 
Habría que considerar urgente analizar otras formas de generar imaginarios que contemplen la relación con la otredad desde una perspectiva comunitaria que entienda a los "Otros" no como simplemente intérpretes de un imaginario personal y por lo tanto exótico -como nos ha demostrado finalmente el caso pasoliniano-, sino como actores con una participación activa y viva en la creación de significado de nuestra realidad. Para poder pensar en otras formas críticocreativas hemos tenido que analizar primero qué significa hacer archivo, entender qué raíces tiene esta práctica, deconstruirla y repolitizarla. Del mismo modo, la obra de Pier Paolo Pasolini y sus prácticas no dejan de visibilizar una necesidad de hacer archivo, aunque su relato siga teniendo una perspectiva eurocéntrica. Por esta razón, en la última parte de esta investigación hemos examinado cómo la cultura dominante occidental contemporánea ha renovado y reinterpretado antiguas técnicas taxonómicas para repetir y reiterar -en formas más modernas y atractivas- los estereotipos de una categorización violenta entre Occidente-Oriente, nortesur, civilizado-salvaje, blanco-negro, etc. Esto nos ha hecho conscientes de que hacer archivo es una práctica nacida en Occidente en la época moderna usada a partir del colonialismo para documentar y relatar la otredad y que los medios audiovisuales a partir de su creación han fomentado especialmente. El cine documental y el cine ficción pueden considerarse documentos de la historia tanto como los textos escritos. Ambos contienen como mínimo tres historias: la oficial (la trama del relato principal), la perspectiva subjetiva o contra-crítica (memoria de quién relata la historia) y las historias excluidas del relato oficial. El hecho de que las otras historias estén excluidas no significa que no existan. Estas historias, independientemente de la forma en que se quieran tratar (o no), están latentes bajo las apariencias, determinando el imaginario global con la misma fuerza con la que la historia dominante pretende excluirlas. 


\section{Bibliografía}

Bazzocchi, M.A. (2013). I riccioli di Ninetto. In G.M. Annovi (ed.) Fratello selvaggio: Pier Paolo Pasolini tra gioventù e nuova gioventù. Massa: Transeuropa.

Bhabha, H. K. (2002). El Lugar de la cultura. Buenos Aires: Ed. Manantial.

Caminati, L. (2010). Orientalismo eretico: Pier Paolo Pasolini e il cinema del Terzo Mondo. Milano: Edizioni Mondadori.

Clifford, J. (1997). Strade. Viaggio e traduzione alla fine del secolo $X X$. Torino: Ed. Bollati Boringhieri.

Eco, U. (1962). Opera aperta. Milano: Edizioni Bompiani, Milano.

Giuliani, G., Longobardi-Diop, C. (2013). Bianco e nero. Storia dell'identità razziale degli italiani. Milano: Ed. Mondadori.

Grecchi, G., Gravano, V. (2016). Presente imperfetto. Ereditá coloniali e immaginari raziali contemporanei. Milano-Udine: Ed. Mimesis.

Maraschin, D. (2014). Pasolini. Cinema e Antropologia. Bern: Ed. Peter Lang.

Mezzadra, S. (2004). Derecho de fuga. Migraciones, ciudadanía y globalización. Madrid: Traficantes de Sueños.

Moravia, A. (2007). L'idea dell'India. Milano: Ed. Bompiani.

Naldini, N. (1989). Pasolini. Una vita. Torino: Einaudi.

Pasolini, P.P. (1972). Empirismo eretico. Milano: Garzanti, Milano.

Pasolini, P.P. (1998). Romanzi e Racconti. Milano: I Meridiani, Ed. Mondadori, Tomo I - II.

Riva, M. y Parussa, S. (1997). L'autore come antropologo: Pier Paolo Pasolini e la morte dell'etnos. Annali d'italianistica, 15, 255-265.

Said, E. W. (1999). Orientalismo. Milano: Feltrinelli.

Sobrero, A.M. (2015). Ho eretto questa statua per ridere. L'antropologia e Pier Paolo Pasolini. Roma: Ed. Cisu. 
Tornitore, T. (2007). Prólogo. En A. Moravia L'idea dell'India. Milano: Ed. Bompiani.

Trento, G. (2010). Pasolini e l'Africa. L'Africa di Pasolini. Panmeridionalismo e rappresentazioni dell'Africa postcoloniale. MilanoUdine: Ed. Mimesis. 